\title{
Ensino Desenvolvimental: contribuições à superação do dilema da didática
}

\author{
Raquel Aparecida Marra da Madeira Freitas' \\ Sandra Valéria Limonta Rosa" \\ 'Pontifícia Universidade Católica de Goiás (PUC-GO), Goiânia/GO - Brasil \\ "Universidade Federal de Goiás (UFG), Goiânia/GO - Brasil
}

RESUMO - Ensino Desenvolvimental: contribuições à superação do dilema da didática. $\mathrm{O}$ artigo problematiza a formação de professores nos cursos de Licenciatura, em particular no de Pedagogia, apontando o dilema que aí se faz presente acerca da didática fundamental e didáticas específicas. Partindo da defesa da ideia de que para ensinar na educação básica é indispensável superar esse dilema, descreve-se a teoria do ensino desenvolvimental e argumenta-se sobre suas contribuições para o enfrentamento desse dilema, tendo em vista o alcance do objetivo mais primordial da educação básica: a aprendizagem consciente e crítica dos conteúdos escolares como condição essencial aos alunos na compreensão e análise do mundo em que vivem.

Palavras-chave: Didática. Educação Básica. Ensino Desenvolvimental.

ABSTRACT - Developmental Teaching: contributions to overcoming the didactics dilemma. The article discusses the training of teachers in undergraduate courses, particularly in Pedagogy, highlighting the dilemma involving fundamental didactics and specific didactics. Based on the advocacy of the idea that overcoming this dilemma is essential to teach at K-12 education, it describes the theory of developmental education and argues for its contributions to face this dilemma, given the scope of K-12 education primary goal: the conscious, critical learning of school subjects as a primary condition for students to understand and analyze the world where they live.

Keywords: Didactics. K-12 Education. Developmental Teaching.

Educação \& Realidade, Porto Alegre, v. 40, n. 2, p. 613-627, abr./jun. 2015. 613 http://dx.doi.org/10.1590/2175-623646133 


\section{Introdução}

A defesa de melhor qualidade do ensino na educação básica brasileira é hoje um lema amplamente presente em discursos e documentos oficiais, bem como na literatura científica e acadêmica da área da educação, ao lado das severas críticas sobre o quanto a escola ainda está longe de possibilitar educação científica, cultural, ética e política de melhor qualidade, sobretudo para as crianças e jovens das escolas públicas (Libâneo, 2011). Neste contexto, algumas razões justificam a necessidade de mudanças na formação e na prática dos professores da educação básica.

A primeira é que a didática, embora seja o meio mais fundamental de concretização do ensino, ainda não é bem compreendida, sendo ora vista de uma forma reducionista, como disciplina prescritiva que se resume a técnica de ensino, ora como disciplina geral a ser aplicada à prática de ensino de disciplinas particulares.

A segunda razão é que mediante a vasta teorização no campo da didática já não é possível admitir que concepções reducionistas a seu respeito continuem presentes de forma significativa. Diversas teorias oferecem contribuições valorosas para impulsionar mudanças nas concepções de didática dos professores, tanto na formação inicial nos cursos de Licenciatura, entre eles o de Pedagogia ${ }^{1}$, quanto na atividade concreta de ensino no cotidiano da educação básica.

Uma terceira razão é que mudanças efetivas na qualidade das aprendizagens dos alunos, desde a educação infantil, tem como um de seus fatores essenciais a mudança qualitativa naquilo que é central da atividade de ensino dos professores: o que, o por que e o como ensinar. Mediante essas razões, defende-se que mudanças didáticas devem estar no centro dos esforços coletivos, teóricos e políticos, para conferir à educação básica melhores condições de corresponder às necessidades educativas contemporâneas das crianças e jovens, sobretudo quando se assume que a educação básica é um fator de democratização da sociedade brasileira no contexto atual.

Delimitado o problema a ser tratado neste texto, cabe aqui algumas considerações acerca do trabalho de ensinar na educação básica. Entende-se que, longe de ser uma atividade simples, o ensino é exigente e complexo, particularmente nos anos iniciais, se considerado o seu objetivo mais primordial: proporcionar às crianças e jovens o acesso e à cultura sistematizada e acumulada historicamente pela humanidade, como o domínio da linguagem escrita e iniciação ao conhecimento sistematizado nos campos da Literatura, Arte, Matemática, Ciências Naturais e Ciências Humanas. Assim, trata-se, como entende Lima (2007), de uma docência multidisciplinar, que necessita ser constituída sobre uma base epistemológica que permita a compreensão do processo de produção do conhecimento e a busca de diferentes possibilidades curricula-

614 Educação \& Realidade, Porto Alegre, v. 40, n. 2, p. 613-627, abr./jun. 2015. 
res e didáticas para iniciar os estudantes, de modo prazeroso, rigoroso e crítico, no universo da ciência e da cultura.

Entendemos a docência como práxis, ação humana transformadora, prática eivada e nutrida de teoria, e por isso capaz de superar os primeiros estágios do pensamento - constatação e compreensão da realidade - para constituir um pensamento novo, que ao ser colocado em prática, pode ser transformador da realidade. Como práxis e como ação humana transformadora, o ensino dos conteúdos escolares caracteriza historicamente o trabalho do professor como função específica de ensinar conhecimentos, ou melhor, saber fazer aprender algo a alguém (Roldão, 2007).

Consequente a esta concepção de docência, ensinar é proporcionar ao aluno formas de apropriar-se dos conteúdos culturais e científicos produzidos historicamente pela humanidade, apropriando-se também de habilidades cognitivas correlatas a estes conteúdos, tais como capacidade de estabelecer relações conceituais, de elaborar análises e sínteses, de pensar teoricamente os objetos de conhecimento, de refletir criticamente sobre a realidade e de utilizar os conhecimentos para orientar-se e agir nesta realidade.

Em síntese, sendo a atividade de ensino-aprendizagem essencialmente uma práxis transformadora dos alunos como sujeitos, a didática tem papel fundamental devendo ser compreendida de forma mais crítica e mais aprofundada. Provavelmente nenhum professor de cursos de Pedagogia e mesmo nenhum professor da educação básica concorde que a concepção tradicional e prescritiva de didática possa contribuir para o ensino na escola brasileira contemporânea, por ser incompatível com concepções pedagógicas atuais que ressaltam a participação dos alunos nas aulas, a valorização de fatores sociais e culturais na aprendizagem, entre outros aspectos.

Também provavelmente, estes professores teriam dificuldades em explicitar outra compreensão de didática ou outras formas de ensinar, não tributárias do ensino tradicional totalmente dirigido pelo professor ou que não caiam no seu oposto, no ensino totalmente desprovido da ação do professor, ficando os alunos muito mais à mercê de suas próprias experiências e vivências como condutoras do processo de ensino-aprendizagem, do que da ação mediadora do professor.

Por outro lado, nota-se também que nos cursos de Pedagogia se faz presente a preocupação em assegurar o caráter didático da formação dos futuros pedagogos, para atuarem nos anos iniciais do ensino fundamental. No entanto, o que aí predomina pode ser compreendido como um dilema entre didática fundamental e didática específica, dificultando resolver a lacuna na formação dos professores quanto ao que, por que e como ensinar.

Nas sessões seguintes deste artigo explicita-se esse dilema, apresentando-se posteriormente algumas premissas da teoria do ensino de- 
senvolvimental formulada por Vasili Vasilievich Davydov e, finalmente, argumenta-se acerca de suas contribuições para a superação do dilema da didática.

\section{Didática Fundamental e Didática Específica: compreendendo o dilema}

A complexidade do ensino nos anos iniciais requer dos professores conhecimento teórico e metodológico mais aprofundado, como condição para realizá-lo como práxis transformadora. Esse conhecimento emana principalmente da didática.

De acordo com Fichtner, a didática “[...] como ciência profissional do professor integra a base científica que orienta suas práticas pedagógicas, provendo-lhes teórica e metodologicamente os fundamentos essenciais do ensino" (Fichtner, 2012, p. 11). Insere-se nessa concepção a didática entendida também como uma epistemologia, um corpo de conhecimentos oriundos de diferentes campos que, tomados em seu conjunto, permitem planejar o ensino e agir no contexto da sala de aula. No entanto, seja no processo de formação no curso de Pedagogia, seja no ensino nos anos iniciais, está presente o dilema entre a didática fundamental e a didática específica. O termo dilema está sendo aqui compreendido tal como explicitado por Saviani:
[...] uma situação embaraçosa com duas saídas igual- mente difíceis. Dilema é um termo derivado do grego $(\delta 1 \lambda \eta \mu \mu \alpha)$. Trata-se de uma palavra composta de dois ele- mentos: a partícula, que é elisão da preposição e também advérbio que, no caso, significa 'separando', 'dividindo', 'de um e de outro lado'; e o vocábulo, que significa 'lema', 'tema', 'proposição', 'premissa de um silogismo'. Dilema, portanto, tem o sentido de 'premissa dupla', o que levou, também, ao sentido de uma argumentação com duas con- clusões contraditórias igualmente possíveis logicamente. A partir dessa acepção técnica, generalizou-se o signifi- cado de dilema como expressando uma situação embara- çosa com duas saídas igualmente difíceis (Saviani, 2007, p. 106).

No Brasil, há expressiva produção teórica no campo da didática que trata de explicitar desde questões teóricas e epistemológicas até questões metodológicas do processo ensino-aprendizagem, remetendo-se também à discussão do processo de formação profissional na graduação e na pós-graduação (Candau, 1984; Candau, 1997; Candau, 2011a; Candau, 2011b; Candau, 2012a; Candau, 2012b; Candau, 2013; Cunha, 1989; Oliveira, 1992; Oliveira, 1997a; Oliveira, 1997b; Libâneo, 2008; Libâneo, 2010a; Libâneo, 2010b; Libâneo, 2013a; Libâneo, 2013b; Libâneo; Alves, 2012; Pimenta, 1997; Pimenta, 2000; Pimenta, 2010; Longarezi; Puentes, 2011a; Longarezi; Puentes, 2011b). 
São produções que muito contribuem para o esclarecimento teórico da didática, da didática como práxis, como mediação, como conhecimento específico do processo de ensino-aprendizagem, originador de formas de intervenção na prática pedagógica. Entre estes autores, destaca-se Libâneo (2008; Libâneo, 2010a; Libâneo, 2010b; Libâneo, 2011), que busca esclarecer a relação entre didática fundamental (didática geral) e didática específica (das disciplinas). A didática fundamental diz respeito à compreensão da didática como uma fundamentação geral do ensino.

Em outras palavras, a didática opera a interligação entre teoria e prática. Ela engloba um conjunto de conhecimentos que entrelaçam contribuições de diferentes esferas científicas (teoria da educação, teoria do conhecimento, psicologia, sociologia, etc.), junto com requisitos de operacionalização. Isto justifica um campo de estudo com identidade própria e diretrizes normativas de ação docente, que nenhuma outra disciplina do currículo de formação de professores cobre ou substitui. Essa é a razão pela qual é tomada como 'disciplina integradora'(Libâneo, 2011, p. 134).

Conforme o autor, aos elementos constitutivos da didática se associam as teorias do ensino, as teorias do conhecimento, as ciências auxiliares da educação (Sociologia, Psicologia, etc.) e a epistemologia das disciplinas ensinadas. Portanto, a didática caracteriza-se como “[...] disciplina que articula numa teoria geral de ensino as várias ciências da educação e compõe-se com as metodologias específicas das disciplinas curriculares" integrando o que é geral ao que é básico para o ensino dos conteúdos (Libâneo, 2013a, p. 68).

Para o autor, há um vínculo estreito da didática com o ensino das disciplinas escolares específicas, que sustenta uma relação essencial entre dois lados da didática: o epistemológico, que diz respeito à investigação da natureza e da organização dos saberes escolares e o psicopedagógico, que diz respeito aos modos de sua apropriação pelo aluno. Portanto, didática básica e didática específica são indissociáveis, interdependentes.

A didática não se sustenta teoricamente se não tiver como referência de sua investigação os conteúdos, as metodologias de ensino e as formas de aprendizagem das disciplinas específicas. Do mesmo modo, não há como ensinar disciplinas específicas sem o aporte da didática, que traz para o ensino as contribuições da teoria da educação, da teoria do conhecimento, da psicologia do desenvolvimento e da aprendizagem, dos métodos e procedimentos de ensino, além de outros campos como a antropologia, a filosofia, etc. [...] A didática tem nas metodologias específicas uma de suas fontes mais importantes de pesquisa, ao lado da teoria da educação, da teoria do conhecimento, 
da psicologia, da sociologia e outras ciências auxiliares da educação. Juntando esses elementos, ela generaliza as manifestações e leis de aprendizagem para o ensino das diferentes disciplinas. Ao efetuar essa tarefa de generalização, a didática se converte em uma das bases essenciais das didáticas específicas. Assim, não se pode, a rigor, falar de uma didática 'geral', nem de métodos gerais de ensino aplicáveis a todas as disciplinas. A didática somente faz sentido se estiver conectada à lógica científica da disciplina ensinada. Ela oferece às disciplinas específicas o que é comum e essencial ao ensino, mas respeitando suas peculiaridades epistemológicas e metodológicas (Libâneo, 2008, p. 67).

O dilema da didática no curso de Pedagogia diz respeito também à formação e ao ensino na docência multidisciplinar: cabe às disciplinas denominadas de metodologias e/ou didáticas específicas oferecerem a melhor formação possível nas diferentes áreas, buscando articular, num espaço-tempo reduzido, conteúdos e processos de ensino e aprendizagem que contemplem a especificidade de cada área do conhecimento. Assim, é necessário compreender a didática também como uma dimensão nuclear e organizadora das atividades de ensino e de aprendizagem a serem desenvolvidas a partir dos conteúdos escolares.

Com efeito, as crianças e jovens vão à escola para aprender cultura e internalizar os meios cognitivos de compreender e transformar o mundo. Para isso, é necessário pensar - estimular a capacidade de raciocínio e julgamento melhorar a capacidade reflexiva e desenvolver as competências do pensar. A didática tem o compromisso com a busca da qualidade cognitiva das aprendizagens, esta por sua vez, associada à aprendizagem do pensar. Cabe-lhe investigar como ajudar os alunos a se constituírem como sujeitos pensantes e críticos, capazes de pensar e lidar com conceitos, argumentar, resolver problemas, diante de dilemas e problemas da vida prática (Libâneo, 2004, p. 5).

A partir deste princípio defendido por Libâneo - a integração entre didática e didáticas específicas - torna-se sem sentido o dilema antes apontado e que se faz presente nos cursos de Pedagogia e na prática pedagógica na educação básica. No entanto, resta a questão de como ensinar na perspectiva da superação deste dilema.

\section{Ensino Desenvolvimental: uma alternativa para a superação do dilema}

No contexto do projeto de formação do novo homem na sociedade socialista soviética após a revolução russa de 1917, o pedagogo e psicólogo Vasili Vasilievich Davydov defendia um projeto de escola que

618 Educação \& Realidade, Porto Alegre, v. 40, n. 2, p. 613-627, abr./jun. 2015. 
ensinasse os alunos a pensar sobre os objetos e questões da realidade de modo dialético. Para isso, defendia que o ensino impulsionasse o desenvolvimento mental, subjetivo, dos alunos. Esse foi o foco de sua pesquisa, fundamentada em gerações de teóricos russos da tradição da teoria histórico-cultural, como Vygotsky, Luria, Leontiev, Galperin, Elkonin, Zaporojets, e outros (Libâneo; Freitas, 2013).

De acordo com Davydov (1982; Davydov, 1988; Davydov, 1999) e Davydov e Markova (1987), o aspecto mais essencial do ensino é que este influencie no desenvolvimento dos alunos, contribuindo para mudanças em suas formas de pensar, analisar, compreender os objetos e suas relações na realidade, o que deve ocorrer desde os anos iniciais da escolarização. Compreendendo a escola e o ensino como os principais meios de promoção do desenvolvimento psicológico e sociocultural desde a infância, sua teoria de ensino propõe que, desde as séries iniciais, as crianças sejam levadas a uma atitude para o estudo.

Por isso, como descrevem Libâneo e Freitas (2013) o autor preocupou-se em buscar respostas às perguntas: "Qual é a relação entre educação e ensino e desenvolvimento mental? Há um tipo de ensino que pode influir mais e melhor para esse desenvolvimento? É possível por meio do ensino e da educação formar numa pessoa certas capacidades ou qualidades mentais que não tinha anteriormente?" (Libâneo; Freitas, 2013, p. 326).

Com base em Vigotski (Vigotski, 1982; Vigotski, 1992) e em Davydov (1999), compreende-se que a atividade mental interna é estruturada na criança sob grande influência da atividade externa com os outros e com os objetos da cultura, num processo de comunicação compartilhada. Por isso, o avanço autônomo e criador do pensamento só é possível sobre a base da experiência histórica que, nesse processo, vai sendo interiorizada. Sobre esta base, o desenvolvimento humano dependerá da interiorização dos êxitos do desenvolvimento histórico-social, possibilitada pela comunicação compartilhada e depois pela atividade mental (re)produtiva individual realizada com os objetos numa relação dialética com o meio externo (Freitas; Limonta, 2012).

No desenvolvimento de suas pesquisas sobre a atividade mental humana, Davydov (1988) percebe a aprendizagem dos conteúdos escolares como um tipo especial de atividade, considerando que o ensino organizado e sistematizado que ocorre durante o processo de escolarização da criança tem um papel fundamental não apenas na transmissão da cultura humana acumulada historicamente, mas na formação das funções psicológicas superiores (memória, atenção, consciência e reflexão), isto porque o ensino faz certas exigências mentais que necessariamente ampliam as capacidades de pensamento do indivíduo, favorecendo novas aprendizagens e novas e melhores funções, numa espiral de desenvolvimento tanto da mente quanto da cultura adquirida. Para ele, as reformas escolares devem levar em conta o papel do ensino na 
formação da personalidade dos alunos, o que requer meios psicopedagógicos para que o professor exerça, por meio do ensino, substancial e necessária influência no desenvolvimento das capacidades dos alunos de uma forma integral.

Uma vez que estas capacidades estão objetivadas na cultura, ao se apropriar de um objeto de conhecimento (cultural, científico, ético, político, estético etc.), o aluno tem a oportunidade de reproduzir em si mesmo as formas mentais e sociais dessas capacidades. Para Davydov a aprendizagem não é a assimilação-reprodução do mundo tal como as crianças o veem ou tal como os adultos lhes ensinam. Para que ocorra a representação psicológica do mundo é necessário o sujeito ver-se "[...] a si mesmo e ao mundo pelos olhos dos outros" (Davydov, 1988, p. 7).

Por exemplo, no estudo do funcionamento do sistema respiratório, o aluno se apropria não só de um conhecimento científico sobre o corpo humano, mas desenvolve ações mentais complexas ligadas a este conhecimento ao organizar mentalmente a linguagem necessária para explicá-lo, formando o conceito de sistema respiratório como uma ferramenta mental correlata àquela utilizada na pesquisa que deu origem a esse conhecimento. Ou seja, o aluno realiza um movimento de pensamento dentro de certa lógica investigativa que faz parte da cultura científica à qual pertence o objeto sistema respiratório. E esta é uma lógica epistemológica própria das ciências que investigam e explicam o corpo humano. Mas é, sobretudo, um modo de representar o corpo humano e de ver seu próprio corpo pelos olhos do outro, neste caso o cientista, o pesquisador.

É frequente a prática dos professores de ensinarem os conteúdos e, posteriormente, elaborarem tarefas para os alunos. Na proposta de Davydov a formulação da tarefa é necessária para o ensino e não posterior a ele. A tarefa envolvendo problemas com o novo conhecimento a ser aprendido deve requerer dos alunos ações mentais correlatas a esse conhecimento. Assim, o aluno adquire o novo conhecimento e, o que é mais importante, forma novas ações mentais, estabelece novas relações, desenvolve novos caminhos e lógicas de pensamento, a partir do trabalho mental com o objeto de conhecimento.

A premissa básica do ensino desenvolvimental é que os métodos de ensino decorrem dos conteúdos escolares. Para organizar o ensino o professor formula um conjunto de tarefas que tem o objetivo de levar o aluno a formar os conceitos que, inter-relacionados em determinada área do conhecimento, compõem uma rede conceitual. No entanto, o professor necessita associar o aspecto lógico e o aspecto epistemológico do conteúdo a ser ensinado. Ou seja, não basta ao professor saber o conteúdo como conhecimento produzido cientificamente, ele precisa compreendê-lo como produto e também como processo.

Em outras palavras, o professor precisa conhecer o modo investigativo pelo qual o conhecimento foi produzido, pois é aí que se situa o 
modo de pensar, analisar e compreender o objeto a ser ensinado a seus alunos. Se ele, o professor, não é capaz de pensar o objeto de conhecimento que ensina como um processo e, ao mesmo tempo, um produto de investigação, dificilmente será capaz de propor tarefas com caráter de problemas para que os alunos resolvam investigativamente. Todos os conceitos, por sua vez, relacionam-se uns com outros em uma rede conceitual. Por exemplo, o conceito de sistema respiratório precisa ser compreendido estrutural e funcionalmente com outros sistemas do corpo humano e, ainda, em sua conexão essencial com o conceito de vida humana, que por sua vez é central na Biologia.

Hedegaard e Chaiklin (2005) explicam que o conceito é um conhecimento teórico pronto, incorporado à cultura humana. Ao ensinar à criança certo conceito, o professor ensina também uma ferramenta de pensamento que serve de elo, de associação com outros conceitos e com a vida cotidiana e pessoal da criança. A criança passa a compreender os objetos culturais do seu dia a dia, da sua vida, de uma forma mais elaborada e consciente porque os pensa e age utilizando os conceitos que adquire na escola.

De acordo com Davydov o aluno aprende realmente um conteúdo quando aprende também as ações mentais ligadas a este conteúdo, os modos mentais de proceder com os conceitos que formam o conteúdo. Em outras palavras, na atividade de aprendizagem os alunos se apropriam (também) das ações mentais que permitiram às gerações anteriores produzirem os conceitos que ele, aluno, está aprendendo agora como conteúdo escolar e que, para ele, é novo. Dessa forma, ele se apropria de um conhecimento histórico, culturalmente e coletivamente produzido por gerações e gerações anteriores e que por meio da aprendizagem passa a ser também seu. É dessa forma que os alunos convertem ativamente o conhecimento coletivo em um conhecimento individual (Freitas, 2011).

Davydov propõe que por meio das tarefas o professor introduza um caminho a ser percorrido pelos alunos, por meio de interações e comunicação compartilhada com o professor e com os outros alunos, envolvendo os materiais didático-pedagógicos (livros, textos, filmes, ilustrações, etc.). Essas ações visam a recriação, para o aluno, de processos criativos realizados por outros. Assim, ele também tem a oportunidade de, embora não criando um novo conhecimento, percorrer o processo criativo que o originou. Escreve o autor:

Embora o pensamento das crianças tenha alguns traços em comum com o pensamento dos cientistas, artistas e filósofos, os dois não são idênticos. As crianças em idade escolar não criam conceitos, imagens, valores e normas, mas apropriam-se deles no processo da atividade de aprendizagem. Mas, ao realizar esta atividade, as crianças executam ações mentais semelhantes às ações pelas quais estes produtos da cultura espiritual foram histori- 
Ensino Desenvolvimental

camente construídos. Em sua atividade de aprendizagem, as crianças reproduzem o processo real pelo qual os indivíduos vêm criando conceitos, imagens, valores e normas. Portanto, o ensino de todas as matérias na escola deve ser estruturado de modo que, como escreveu Ilenkov, seja reproduzido, de forma condensada e abreviada, o processo histórico real da gênese e desenvolvimento do conhecimento (Davydov, 1988, p. 21-22).

Ao elaborar as tarefas, o professor deve assegurar que as ações de aprendizagem atendam ao princípio da conversão da atividade externa, social, em atividade interna, individual. Esse princípio requer o atendimento a dois aspectos essenciais: as ações mentais deverão ser inicialmente coletivas e, depois, individuais; as ações propostas pelo professor levarão os alunos a realizarem o movimento de pensamento na direção do geral (abstrato) para o particular (concreto). Significa que, primeiramente, os alunos aprendem e interiorizam os conceitos no plano social compartilhado e depois é que lidam com estes conceitos em situações individuais e particulares, nas diversas formas que ele se apresenta na realidade concreta (Freitas, 2011).

Uma vez apreendido teoricamente o objeto, como um conceito, o professor propõe aos alunos sua generalização, utilizando-o na análise de diversas e variadas situações e contextos envolvendo o objeto, agora de forma particular, singular. Desse modo, tendo sido antes confrontados com um problema cuja solução exigiu deles a apreensão teórica do conceito por meio de ações teórico-práticas, os alunos agora vão em busca da concretização desse conceito. Portanto, não há um momento prático posterior a uma apreensão teórica do objeto de estudo e nem experiência prática desprovida de fundamentação conceitual para posterior apreensão teórica. Ao contrário, a ação do aluno com o objeto durante a realização da tarefa é sempre teórico-prática, individual-coletiva, abstrata-concreta, sendo que essas dimensões permanecerão em movimento na atividade pensante do aluno, que poderá ampliar e expandir o conceito, inclusive para outras disciplinas.

Davydov em sua teoria também confere muita importância ao desejo e aos motivos da criança para aprender. A tarefa proposta pelo professor deve conter elementos que possam provocar no aluno a necessidade de estabelecer uma relação com o novo objeto a ser conhecido, seja por sua forma de desafio ou de problema a ser solucionado. Assim, inicialmente o aluno não tem um motivo para aprender o objeto, mas, à medida que vai estabelecendo com ele uma relação de aprendizagem, esse motivo passa a existir. Todavia, afirma Davydov, que além do motivo é necessário, por parte do aluno, o desejo de aprender. Não sendo inato e nem espontâneo, o desejo de aprender é um elemento psicológico, social e ao mesmo tempo individual, fazendo parte da estrutura psicológica da aprendizagem. Por isso ele precisa ocorrer primeiro no plano externo, social, para então ser interiorizado e passar a ocorrer 
num plano interno, individual. O desejo de aprender determinado conteúdo está intimamente ligado à motivação para a realização da tarefa, que é de certa forma, o elo social que o professor propõe para criar na criança o desejo de participar daquela atividade, de responder às perguntas do professor, de dizer aos outros o que já sabe, enfim, de aprender (Davydov, 1982; 1987; 1988).

\section{Conclusões}

É possível identificar, na teoria de Davydov e no método de ensino que este autor propõe, várias contribuições relevantes para pesquisadores e professores que assumem uma posição superadora do dilema entre didática e didáticas específicas. Destacam-se aqui pelo menos três contribuições. A primeira está relacionada ao papel fundamental atribuído pelo autor aos conhecimentos científico, artístico e filosófico no desenvolvimento dos alunos. Nesse sentido, ao defender o princípio teórico de que os métodos de ensino decorrem dos conteúdos, Davydov privilegia a necessária integração entre conhecimento didático (métodos de ensino) e conhecimentos específicos (conteúdos). A segunda decorre do princípio teórico de que para ensinar o professor necessita ter para si a lógica investigativa do objeto a ser ensinado, implica necessariamente uma integração entre a lógica epistemológica do conteúdo e o tratamento pedagógico-didático desse conteúdo, na perspectiva da atividade criativa (recriativa) do aluno na relação de aprendizagem com o objeto. A terceira contribuição diz respeito ao princípio de que para formular a tarefa do aluno o professor deve partir de problemas de natureza teórica em relação aos objetos, mas não de forma dissociada do modo de ensiná-los e tão pouco dissociada do modo pelo qual esses objetos se apresentam concretamente na realidade. Em síntese, essa teoria defende que o modo de ensinar necessita contemplar uma profunda relação com a lógica de pensamento presente no objeto ensinado, lógica essa que, por sua vez, também necessita estar presente no caminho de pensamento proposto pelo professor ao aluno nas tarefas, resoluções de problemas, de desafios, etc. O caminho didático que pode ser constituído pelo professor ao se fundamentar na teoria de ensino de Davydov implica, portanto, que ao propor as ações de aprendizagem ao aluno, o professor considere as relações entre área do conhecimento, especificidade do conteúdo e características dos alunos. Isso significa que a tarefa não segue o mesmo caminho para todos os conteúdos, nem para todos os objetos de conhecimento, pois as áreas de conhecimento se distinguem umas das outras, lógica, histórica e epistemologicamente. Por isso, mesmo no interior de uma disciplina, o processo ensino-aprendizagem poderá traçar distintos caminhos de acordo com a lógica do objeto de conhecimento. Além disso, ao ter que considerar as características dos alunos, o caminho didático esboçado pelo professor deverá contemplar os aspectos histórico-culturais, socioculturais e afetivos dos alunos, em cada etapa da educação básica. 
Ao aprender dessa forma, os alunos da educação básica certamente terão mais possibilidades de estabelecer com os conteúdos uma verdadeira relação com os saberes, no sentido descrito por Charlot (2005), integrando-os à sua vida como novas estruturas de pensamento, que contribuem para impulsionar sua capacidade criadora, a ação em seu entorno diário, em seu contexto de vida, em suas relações com os outros, com o mundo e consigo mesmos. Para a educação básica no contexto brasileiro, sobretudo para a escola pública, é promissora a contribuição de Davydov, pois apresenta um método de ensino articulado a princípios teóricos de promoção da aprendizagem e desenvolvimento da atividade mental dos alunos. Por isso defendemos que, por sua robustez teórica e metodológica, é uma alternativa importante a ser considerada nos cursos de Licenciatura, entre eles o de Pedagogia, mas também nos cursos de formação de professores de um modo geral e nos projetos pedagógicos da educação básica.

Recebido em 31 de março de 2014 Aprovado em 14 de setembro de 2014

\section{Nota}

1 Atualmente no Brasil, enquanto os cursos de Licenciatura em Pedagogia centram na formação de professores para atuarem na educação infantil e dos anos iniciais do Ensino Fundamental, as outras Licenciaturas, com algumas exceções, centram na formação de professores dos anos finais do Ensino Fundamental e do Ensino Médio.

\section{Referências}

ALARCÃO, Isabel. Contribuição da Didáctica para a Formação de Professores Reflexões sobre seu ensino. In: PIMENTA, Selma Garrido (Org.). Didática e Formação de Professores: percursos e perspectivas no Brasil e em Portugal. 6. ed. São Paulo: Cortez, 2011. P. 159-190.

CANDAU, Vera Maria Ferrão. A Didática em Questão. Petrópolis: Vozes, 1984.

CANDAU, Vera Maria Ferrão. Da Didática Fundamental ao Fundamental da Didática. In: ANDRÉ, Marli E.; OLIVEIRA, Maria Rita Neto Sales de (Org.). Alternativas no Ensino de Didática. Campinas: Papirus, 1997. P. 71-95.

CANDAU, Vera Maria Ferrão (Org.). Diferenças Culturais e Educação: construindo caminhos. Rio de Janeiro: 7 Letras, 2011a. P. 207-216.

CANDAU, Vera Maria Ferrão. Escola, Didática e Interculturalidade: desafios atuais. In: LIBÂNEO, José Carlos; SUANNO, Marilza Vanessa Rosa (Org.). Didática e Escola em uma Sociedade Complexa. Goiânia: CEPED, 2011b. P. 13-32.

CANDAU, Vera Maria Ferrão. Diferenças Culturais, Cotidiano Escolar e Práticas Pedagógicas. In: CANDAU, Vera Maria Ferrão (Org.). Didática Crítica Intercultural. Petrópolis: Vozes, 2012a. P. 81-106.

CANDAU, Vera Maria Ferrão (Org.). Didática Crítica Intercultural: aproximações. Petrópolis: Vozes, 2012b.

624 Educação \& Realidade, Porto Alegre, v. 40, n. 2, p. 613-627, abr./jun. 2015. 
CANDAU, Vera Maria Ferrão (Org.). Reinventar a Escola. Petrópolis: Vozes, 2013. CHARLOT, Bernard. Relação com o Saber, Formação de Professores e Globalização: questões para a educação hoje. Porto Alegre: Artmed, 2005.

CUNHA, Maria Isabel. O Bom Professor e sua Prática. Campinas: Papirus, 1989. DAVYDOV, Vasili V. Tipos de Generalización en la Enseñanza. Tradução M. Shuare. Habana: Editorial Pueblo y Educación, 1982.

DAVYDOV, Vasili V. Problems of Developmental Teaching - The experience of Theoretical and Experimental Psychological Research. Soviet Education, v. XXX, Aug. 1988.

DAVYDOV, Vasili V. A New Approach to the Interpretation of Activity Structure and Content. In: CHAIKLIN, Seth; HEDEGAARD, Mariane; JENSEN, Uffe Juul. Activity Theory and Social Practice: cultural-historical approaches. Aarhus (Dinamarca): Aarhus University Press, 1999. P. 39-50.

DAVYDOV, Vasili V.; MÁRKOVA, Aelita Kapitánovna. La Concepción de la Actividad de Estudio en los Escolares. In: SHUARE, Martha. La Psicología Evolutiva en la URSS: Antología. Moscú: Editorial Progreso, 1987. P. 316-337.

FICHTNER, Bernhard. O Conhecimento e o Papel do Professor. In: LIBÂNEO, José Carlos; ALVES, Nilda (Org.). Temas de Pedagogia: diálogos entre didática e currículo. São Paulo: Cortez, 2012. P. 209-226.

FREITAS, Raquel Aparecida Marra da Madeira. Aprendizagem e Formação de Conceitos na Teoria de Vasili Davydov. In: LIBÂNEO, José Carlos; SUANNO, Marilza Vanessa Rosa; LIMONTA, Sandra Valéria (Org.). Concepções e Práticas de Ensino num Mundo em Mudança: diferentes olhares para a Didática. Goiânia: PUC Goiás, 2011. P. 71-84.

FREITAS, Raquel Aparecida Marra da Madeira; LIMONTA, Sandra Valéria. A Educação Científica da Criança: contribuições da teoria do ensino desenvolvimental. Linhas Críticas, Brasília, v. 18, p. 47-68, 2012.

HEDEGAARD, Mariane; CHAIKIN Seth. Radical-Local Teaching and Learning. A cultural-historical approach. Aarhus (Dinamarca): Aarhus University Press, 2005.

LIBÂNEO, José Carlos. A Didática e a Aprendizagem do Pensar e do Aprender: a teoria histórico-cultural da atividade e a contribuição de Vasili Davídov. Revista Brasileira de Educação, Rio de Janeiro, n. 27, p. 5-24, 2004.

LIBÂNEO, José Carlos. Didática e Epistemologia: para além do embate entre a didática e as didáticas específicas. In: D’ÁVILA, Maria Cristina; VEIGA, Ilma Passos A. (Org.). Profissão Docente: novos sentidos, novas perspectivas. Campinas: Papirus, 2008. P. 59-88.

LIBÂNEO, José Carlos. O Ensino da Didática, das Metodologias Específicas e dos Conteúdos Específicos do Ensino Fundamental nos Currículos dos Cursos de Pedagogia. Revista Brasileira de Estudos Pedagógicos, Brasília, v. 91, n. 229, set./dez. 2010a.

LIBÂNEO, José Carlos. A Integração entre Didática e Epistemologia das Disciplinas: uma via para a renovação dos conteúdos da didática. In: DALBEN, Ângela Imaculada Loureiro de Freitas et al. (Org.). Convergências e Tensões no Campo da Formação e do Trabalho Docente: didática, formação de professores, trabalho docente. Belo Horizonte: Autêntica, 2010b. P. 81-104.

LIBÂNEO, José Carlos. Educação, Pedagogia e Didática. O Campo Investigativo da Pedagogia e da Didática no Brasil: esboço histórico e buscas de identidade 
epistemológica e profissional. In: PIMENTA, Selma Garrido (Org.). Didática e Formação de Professores: percursos e perspectivas no Brasil e em Portugal. São Paulo: Cortez, 2011. P. 77-129.

LIBÂNEO, José Carlos. Didática como Campo Investigativo e Disciplinar e seu Lugar na Formação de Professores no Brasil. In: OLIVEIRA, Maria Rita Neto Sales de; PACHECO, José Augusto (Org.). Currículo, Didática e Formação de Professores. Campinas: Papirus, 2013a. P. 131-166.

LIBÂNEO, José Carlos. Didática na Formação de Professores: entre a exigência democrática de formação cultural e científica e as demandas das práticas socioculturais. In: SANTOS, Akiko; SUANNO, João Henrique; SUANNO, Marilza Vanessa R. (Org.). Didática e Formação de Professores: complexidade e transdisciplinaridade. Porto Alegre: Sulina, 2013b. P. 51-81.

LIBÂNEO, José Carlos; FREITAS, Raquel A. Marra da Madeira. Vasily Vasilyevich Davydov: a escola e a formação do pensamento teórico-científico. In: LONGAREZI, Andréa Maturano; PUENTES, Roberto Valdés (Org.). Ensino Desenvolvimental: vida, pensamento e obra dos principais representantes russos. Uberlândia: EDUFU, 2013. P. 315-350.

LIMA, Vanda Moreira Machado. Formação do Professor Polivalente e os Saberes Docentes: um estudo a partir de escolas públicas. 2007. $200 \mathrm{f}$. Tese (Doutorado em Educação) - Programa de Pós-graduação em Educação, Universidade de São Paulo, São Paulo, 2007.

LONGAREZI, Andréa Maturano; PUENTES, Roberto Valdés (Org.). Panorama da Didática: ensino, prática e pesquisa. Campinas: Papirus, 2011a.

LONGAREZI, Andréa Maturano; PUENTES, Roberto Valdés. Pesquisa e Produção Pesquisa Didática no Âmbito da Pós-Graduação. In: LONGAREZI, Andréa Maturano; PUENTES, Roberto Valdés (Org.). Panorama da Didática: ensino, prática e pesquisa. Campinas: Papirus, 2011b. P. 234-252.

OLIVEIRA, Maria Rita Neto Sales. A Reconstrução da Didática: elementos teórico-metodológicos. Campinas: Papirus, 1992.

OLIVEIRA, Maria Rita Neto Sales. Desafios na Área da Didática. In: ANDRÉ, Marli Eliza D. A.; OLIVEIRA, Maria Rita Neto Sales (Org.). Alternativas no Ensino da Didática. Campinas: Papirus, 1997a. P. 129-143.

OLIVEIRA, Maria Rita Neto Sales. A Pesquisa em Didática no Brasil: da tecnologia do ensino à teoria pedagógica. In: PIMENTA, Selma Garrido (Org.). Didática e Formação de Professores: percursos e perspectivas no Brasil e em Portugal. São Paulo: Cortez, 1997b. P. 131-157.

PIMENTA, Selma G. Para uma Re-Significação da Didática. Ciências da educação, Pedagogia e didática (uma revisão conceitual e uma síntese provisória). In: PIMENTA, Selma Garrido (Org.). Didática e Formação de Professores: percursos e perspectivas no Brasil e em Portugal. São Paulo: Cortez, 1997. P. 19-76.

PIMENTA, Selma G. A Pesquisa em Didática: 1996-1999. In: CANDAU, Vera Maria (Org.). Didática, Currículo e Saberes Escolares. Rio de Janeiro: DP \& A, 2000. P. 78-106.

PIMENTA, Selma G. Epistemologia da Prática: ressignificando a didática. In: FRANCO, Maria Amélia Santoro; PIMENTA, Selma Garrido. Didática: embates contemporâneos. São Paulo: Loyola, 2010. P. 15-41.

ROLDÃO, Maria do Céu. Função Docente: natureza e construção do conhecimento profissional. Revista Brasileira de Educação, Rio de Janeiro, n. 34, p. 94103, jan./abr. 2007.

626 Educação \& Realidade, Porto Alegre, v. 40, n. 2, p. 613-627, abr./jun. 2015. 
SAVIANI, Dermeval. Pedagogia: o espação da educação na universidade. Cadernos de Pesquisa, São Paulo, v. 37, n. 130, p. 99-134, jan./abr. 2007.

VIGOTSKI, Lev Semenovich. Obras escogidas II. Madrid: Visor, 1982.

VIGOTSKI, Lev Semenovich. Aprendizagem e Desenvolvimento Intelectual na Idade Escolar. In: VIGOTSKI, Lev Semenovich; LURIA, Alexander Romanovich; LEONTIEV, Alexis Nikolaevicht. Linguagem, Desenvolvimento e Aprendizagem. Tradução de Maria de Penha Villalobos. 4. ed. São Paulo: Ícone, 1992. P. 103-118.

Raquel Aparecida Marra da Madeira Freitas é professora na PUC Goiás, onde atua no Programa de Pós-graduação em Educação, na Linha de Pesquisa Teorias da Educação e Processos Pedagógicos e no Mestrado em Atenção à Saúde, na Linha de Pesquisa Promoção da Saúde. Pesquisa e ensino temas ligados à didática, ensino e aprendizagem, formação de professores e formação de outros profissionais, fundamentando-se nas teorias de Vygotsky e de Davydov.

E-mail: raquelmarram@gmail.com

Sandra Valéria Limonta Rosa é professora da Faculdade de Educação da Universidade Federal de Goiás, no curso de Pedagogia e no Programa de Pós-Graduação em Educação, atuando na Linha de Pesquisa Formação, Profissionalização Docente e Trabalho Educativo. Temas de ensino e pesquisa: formação de professores, trabalho docente e didática.

E-mail: sandralimonta@gmail.com 